cations was issued in 1988 in the form of guidance notes. ${ }^{3}$ The notes cover most eventualities, but sometimes local interpretation is required. A disadvantage of local interpretation is that unnecessary restrictions may be imposed by radiation protection advisers being overcautious because they do not have the necessary data. Some of these omissions have been filled,,$^{+-8}$ but for some problems a practical assessment of the hazards has yet to be made. Nevertheless, from these notes staff in departments of nuclear medicine should be able to answer queries and reassure other staff and the public.

The British Nuclear Medicine Society recently held a conference to discuss interpreting the regulations, and the Intercollegiate Standing Committee in Nuclear Medicine has invited departments to notify it of difficulties experienced in their implementation. ${ }^{9}$ The Health and Safety Commission has established a joint working party to review the regulations; it is currently concerned with the increased cancer risks estimated from survivors of the Japanese atomic bombs and the interim guidance issued by the National Radiological Protection Board recommending annual occupational dose limits lower than those given in the regulations. ${ }^{10}$ Although these lower annual limits are not usually exceeded by hospital staff, proportionate reduction in other regulatory limits that govern the working environment would have appreciable consequences for current working practices, which would affect not only the department giving the radioactivity but also other parts of the hospital, including wards. For instance, it would be necessary to retain some patients in hospital overnight and for staff to accompany them to other hospital departments. Such changes would result in sharp increases in the costs of providing a nuclear medicine service. It is hoped that ways will be found in any new legislation or guidance to allow these difficulties to be circumvented without exceeding revised annual limits. ${ }^{11}$
Staff with infrequent contact with radioactive patients should be reassured that most staff in departments of nuclear medicine, who may be subject to almost continual exposure, receive annual whole body radiation doses that are less than the current legal limit for members of the public. Other hospital staff and members of the public may commonly be unaware, however, of their exposure to radioactive patients. Those providing the service must ensure that the training and procedures followed by staff in departments of nuclear medicine continue to result in a negligible risk to these other groups.

P J MOUNTFORD Principal Physicist

A J COAKLEY

Department of Nuclear Medicine,

Kent and Canterbury Hospital,

Canterbury,

Kent CT1 3NG

1 Administration of Radioactive Substances Advisory Committee. Notes for guidance on the administration of radioactive substances to persons for diagnosis, treatment and research. London: DHSS, 1988

2 Ionising radiations regulations 1985 . London: HMSO, 1985: (SI 1985 No 1333. )

3 Guidance notes for the protection of persons against ionising radiations arising from medical and dental use. London: HMSO, 1988

Harding LK, Mostafa AB, Roden L, Williams N. Dose rates from patients having nuclear medicine investigations. Nucl Med Commun 1985;6:191-4.

Harding LK, Smith NB, Bignell A, Thomson WH. Nuclear medicine and clinical chemistry deprtments. Nucl Med Commun 1987.8:767.9.

Thomson WH, Mills AP, Hesslewood SR, Copeland J, Harding LK. A lightweight syringe shield. Nucl Med Commun 1987;8:269.

Mountford PJ. Estimation of close contact doses to young infants from surface dose rates on radioactive adults. Nucl Med Commun 1987;8:857-63.

Mountford PJ, Coakley AJ. A review of the secretion of radioactivity in human breast milk: data, Mountford PJ, Coakley AJ. A review of the secretion of radioactivity in human
quantitative analysis and recommendations. Nucl Med Commun 1989;10:15-27.

9 Brownlee B. Guidance notes for the protection of persons against ionising radiations arising from medical and dental use. Nucl Med Commun 1989;10:62.

10 National Radiological Protection Board. Interim guidance on the implication of recent revisions of risk estimates and the ICRP 1987 Como Statement. London: HMSO, 1987. (NRPB-GS9.)

11 Roberts PJ. Changes in dose limitation. Nucl Med Commun 1989;10:1-3.

\title{
Enteropathy induced by non-steroidal anti-inflammatory drugs
}

\section{Often subclinical but may mimic Crohn's disease}

Non-steroidal anti-inflammatory drugs of all groups have long been known to induce ulceration of the stomach and duodenum. Recently they have been recognised - particularly when given long term - to increase the permeability of the small intestine and cause occult blood loss. In a few patients the drugs may cause ulceration and stricturing of the small bowel and a clinical syndrome indistinguishable from Crohn's disease.

The earliest reports of ulceration and stricture in the small bowel associated with non-steroidal anti-inflammatory drugs were in patients who were commonly taking many drugs. ${ }^{1}$ Many cases were classified as idiopathic ulceration of the small intestine. ${ }^{2}$ Then Langman and others showed that some patients admitted to hospital with perforation of the small and large intestine were receiving non-steroidal anti-inflammatory drugs, ${ }^{3}$ whereas among 44 premature infants receiving indomethacin for closure of a patent ductus arteriosus, four had perforation of the small intestine. ${ }^{+}$Non-steroidal anti-inflammatory drugs also emerged as an important factor in the relapse of ulcerative colitis, ${ }^{5}$ and Bjarnason and others showed that patients with rheumatoid arthritis receiving long term non-steroidal anti-inflammatory drugs have increased small intestinal permeability. ${ }^{6}$

Enteropathy affects patients of any age and either sex who have taken non-steroidal anti-inflammatory drugs for six months or longer. ${ }^{7}$ More than two thirds of patients taking the drugs long term have subclinical intestinal inflammation and occult blood loss. ${ }^{89}$ Most of them remain symptom free, but up to a fifth may have bile acid malabsorption and thus may develop diarrhoeal illnesses. The blood loss is usually subclinical, and iron deficiency anaemia and hypoalbuminaemia will develop only if there is additional disease or dietary problems. Probably fewer than $1 \%$ of patients develop strictures and ulceration; early ulceration of the mucosa may progress through transmural inflammation to a stricture dominated by submucosal fibrosis. Granulomas, fissuring ulceration, or arteritis does not occur. ${ }^{10}$

Patients with enteropathy caused by non-steroidal anti-inflammatory drugs may present with loss of appetite and weight, an iron deficiency anaemia of uncertain aetiology, or, occasionally, obstruction or perforation of the small intestine, but most patients have no symptoms or physical signs. "The differential diagnosis of a stricture includes ischaemia or tuberculosis of the small intestine, lymphoma, post-irradiation enteritis, and inflammatory bowel disease, but only inflammatory bowel disease should pose any diagnostic problem. Sigmoidoscopy, colonoscopy, and examination by barium enema may help in the diagnosis. These show no abnormalities 
in enteropathy caused by non-steroidal anti-inflammatory drugs; examination of the small bowel by a barium study may show strictures and skip lesions in both Crohn's disease and enteropathy caused by non-steroidal anti-inflammatory drugs.

Confirming the diagnosis of enteropathy caused by non-steroidal anti-inflammatory drugs is often difficult. Neoplasia should be excluded; withdrawing the drug may stop the malabsorption and blood loss. If the condition is diagnosed as an adverse reaction this should be reported to the Committee on Safety of Medicines in the usual way. Management of the condition is essentially to treat the symptoms. The subclinical biochemical abnormalities persist for up to 16 months after withdrawing the drug. ${ }^{12}$ Strictures of the small intestine are best treated by resection. The prognosis of the subclinical enteropathy is good provided that the non-steroidal anti-inflammatory drug is withdrawn; disease associated with strictures may have a more indolent remitting course and is not reversed by withdrawing the drug.

About 30 million patients around the world take nonsteroidal anti-inflammatory drugs regularly so the enteropathy caused represents a substantial clinical challenge. Many cases may be masquerading as Crohn's disease, accounting partly for the recent increase in this condition. ${ }^{13}$ The problem may be reduced by judicious prescribing of non-steroidal anti-inflammatory drugs but is likely to become even more widespread.

MRC Training Fellow,

ANJAN K BANERJEE

King's College Hospital Medical School,

London SE5 8RS

1 Sturges $\mathrm{HF}$, Krone CL. Ulceration and stricture of the jejunum in a patient on long term indomethacin. Am f Gastroenterol 1973;59:162-9.

Davies DR, Brightmore T. Idiopathic and drug induced ulceration of the small intestine. Br $\mathcal{f}$ Surg 1970;57:134-9.

3 Langman MJS, Morgan L, Worral A. Use of anti-inflammatory drugs by patients admitted with small or large bowel perforations and haemorrhage. $\mathrm{Br} M e d \mathcal{f}$ 1985;290:347-9.

4 Nagaraj HS, Sandhu AS, Cook LN, Buchinoj J, Groff DB. Gastrointestinal perforation following indomethacin therapy in very low birthweight infants. F Pediatr Surg 1981;16:1003-7.

5 Rampton DS, McNeil NI, Sarner M. Analgesic ingestion and other factors preceding relapse in ulcerative colitis. Gut 1983;24:187-9.

6 Bjarnason I, Williams P, So A, et al. Intestinal permeability and inflammation in rheumatoid arthritis: effects of non-steroidal anti-inflammatory drugs. Lancet 1984;ii:1171-4.

7 Bjarnason I, Zanelli G, Smith T, et al. Nonsteroidal antiinflammatory drug-induced intestinal inflammation in humans. Gastroenterology 1987;93:480-9.

8 Bjarnason I, Williams P, Zanelli G, et al. Non-steroidal anti-inflammatory drug (NSAID) induced intestinal inflammation in man. Gastroenterology 1985;88:1327.

9 Simpson LO. NSAID and the leaky gur. Lancet 1985;i:218-9.

10 Lang J, Bjarnason I, Levi AJ, Price AB. Pathology of iatrogenic strictures due to NSAIDs. Gut 1985;26:A542.

11 Bjarnason 1, Williams P, Smethurst P, Peters TJ, Levi AJ. Effect of non-steroidal antiinflammatory drugs and prostaglandins on the permeability of the human small intestine. Gut 1986;27:1292-7.

12 Bjarnason I, Zanelli G, Prouse P, et al. Blood and protein loss via small intestinal inflammation induced by non-steroidal anti-inflammatory drugs. Lancet 1987;ii:711-4.

13 Baneriee AK, Peters TJ. Crohn's or poisoning? Gut 1988;29:1182.

\section{The Independent Living Fund}

\author{
Helping to make a reality of community care
}

The changes to social security payments made in April 1988 were depressing reading for those concerned with maintaining frail and disabled people in the community. In particular, the domestic assistance allowance, which had been used to improve the care of frail elderly people, was abolished. ${ }^{\prime}$ In its place the Independent Living Fund was set up, with the objective of helping severely disabled people on low incomes to live independently in their own houses by providing money for them to employ personal carers or domestic help. ${ }^{2}$ Does it work; how do you claim from the fund; how much can you get; what are the problems? After one year the experience in Bexley can help answer some of these questions.

Broadly the fund will provide whatever money is needed to help a severely disabled person with domestic and personal care, but it is particularly aimed at those less likely to be equipped to organise their own care or with less experience in employing others. Claimants can either live alone or with other people who cannot give all the care needed. They should already be receiving, or be entitled to receive, the attendance allowance, and they or their partner should be receiving income support. If they do not get income support they can still claim if their income is less than the cost of the care needed and their capital is less than $£ 6000$.

A claim is started by filling in a simple application form (Independent Living Fund, PO Box 183, Nottingham NG8 3RD) and sending it to the fund managers. For elderly people, especially those with dementia, it is helpful to send also a covering letter giving more details and asking that all communication should be through the community care manager, social worker, or next of kin. It can be important to have a case manager both to clarify the exact problems and to help with employing the carers. Within two to three weeks a "voluntary visitor" calls, who will complete a thorough assessment. The visitor forwards this information, together with recommendations on acceptance and urgency, to the fund managers. This stage is crucial as the fund is entirely discretionary. There is often a worrying wait at this time, but in our experience telephone calls elicit a helpful and sympathetic response. Finally, the decision is sent to the client.

Is it all worthwhile? For the right person it can be dramatically effective. Although the fund is discretionary, once it has accepted a claim it will pay fully for necessary care. We have successfully claimed up to $£ 180$ a week to employ live in carers for frail elderly people at home, who would otherwise be in nursing homes or long stay hospitals. The fund can also back date its payments to pay for care given while the claim was being made.

Of course there are problems: claims can take some time to be decided, the fund is discretionary, the government publicly earmarked only $£ 5 \mathrm{~m}$ in the first year, and cheques for very large sums of money may be sent weekly to frail or confused people, leading to the possibility of theft, fraud, or exploitation. Our experience in the fund's first year, however, suggests that it is a tremendous resource, which for once can be used to make a reality of community care.

Consultant Physician,

DAVID BLACK

Elderly Medical Unit,

Queen Mary's Hospital,

Sidcup,

Kent DA14 7LT

1 Chambers P. Paid neighbours improve care for frail elderly. Geriatric Medicine, 1986 Nov: $42-5$. 2 Department of Health. The independent living fund. London: Department of Health, 1988. (Press 